\title{
TEMPERATURE COMPENSATION OF NDFEB PERMANENT MAGNETS
}

\author{
S. H. Kim and C. Doose \\ CONF-97050Z-- \\ Advanced Photon Source, Argonne National Laboratory, \\ 9700 South Cass Avenue, Argonne, Illinois 60439
}

\begin{abstract}
Permanent magnet blocks of $\mathrm{NdFeB}$ have a relatively high maximum energy product. Because of its relatively low Curie temperature, however, $\mathrm{NdFeB}$ has a large temperature coefficient for its residual induction. The temperature coefficients of the relative magnetic fields $(\Delta B / B) / \Delta T$ in the air gap of $N d F e B$ dipole magnets were reduced from $-1.1 \times 10^{-3} /{ }^{\circ} \mathrm{C}$ to less than $2 \times 10^{-5} /{ }^{\circ} \mathrm{C}$ under operating temperatures of $\pm 6^{\circ} \mathrm{C}$. This was achieved passively by using $1.25-\mathrm{mm}$-thick strips of $30 \%-\mathrm{Ni}-\mathrm{Fe}$ alloy as flux shunts for the NdFeB blocks. The magnets with soft-steel poles and flux-return yokes were assembled and measured in a temperature-controlled environment.
\end{abstract}

\section{INTRODL:CTION}

Stable permanent magnets could be used for chargedbeam storage rings and for other new magnetic devices which require system reliability and lower construction and operation costs. One drawback of permanent magnets for these types of applications, however, is maintaining the required magnetic field when the residual induction and coersive forces change due to the ambient temperature variation.

The bulk magnetization of a permanent magnet is the result of a collective alignment of atomic spins within magnetic domains. As the temperature increases, thermal fluctuations induce random variations in individual atomic spin orientations. At Curie temperature $T_{c}$. all the spins are randomly oriented and the bulk magnetization disappears. Therefore, at ambient temperature, a permanent magnei $w$ higher $T_{\mathcal{c}}$ has a lower temperature coefficient for the variation of the magnetization.

Permanent magnet blocks of neodymium-iron-boron $(\mathrm{NdFeB})$ have relatively high maximum energy-product in the deniagnetizing quadrant compared to other permanent magnets such as Alnico, ferrite, and rare-earth cobalt [1]. Because of its relatively low Curie temperature of approximately $300^{\circ} \mathrm{C}, \mathrm{NdFeB}$ has a high temperature coefficient for its residual induction.

The purpose of this work is to reduce the temperature coefficient of the magnetic fields of $\mathrm{NdFeB}$ permanent magnets better than $10^{-4} /{ }^{\circ} \mathrm{C}$ within the range of an operation temperature using parallel flux-shunts. At lower temperatures the shunt permeability increases, enabling the shunt to carry or divert more flux from the alr gap of the magnet. At higher temperatures, the reverse $c c$ idition exists: the shunt permeability decreases and less air-gap flux is diverted. In order to have higher temperature sensitivity, the shunt material should have a Curie point close to ambient temperature. Shunt materials made of Curie alloys (30-32\% Ni-Fe) and Montel alloys (67\% Ni$\mathrm{Cu}-\mathrm{Fe}$ ) have relatively low Curie temperatures of less than $100^{\circ} \mathrm{C}$. Temperature compensations for ferrite permanent magnets have been extensively studied at Fermilab for use at relatively low magnetic field [2].

(a)
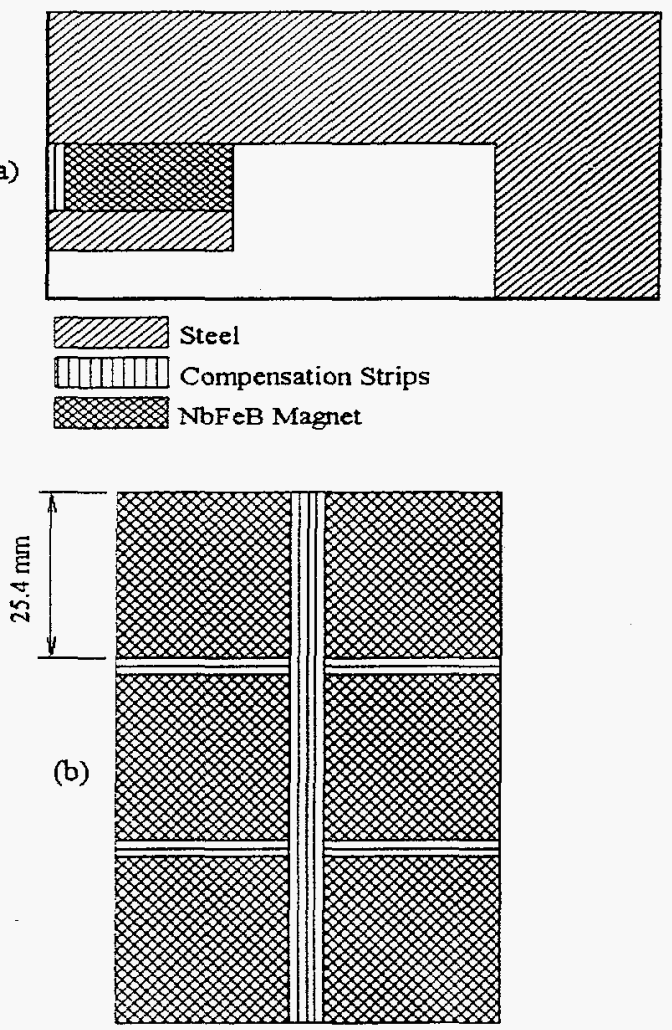

Figure 1: (a) Symmetrical cross section of a quadrant of a dipole magnet with a soft-steel pole and flux-return yoke. The NdFeB block is magnetized in the vertical direction. (b) Top view for the arrangement of the permanent magnet blocks and the temperature compersation strips inserted between the blocks.

\section{TEMPERATURE COMPENSATION}

The symmetrical cross section of a quadrant of a typical dipole nagnet used for this study is shown in Fig. 1. The major components of the magnets are $\mathrm{NdFeB}$ permanent magnet blocks. magnetic flux shunts for temperature compensation, flux-return yokes, and soft-steel poles for field-shaping. The NdFeB blocks have a cross section of $25.4 \times 25.4$ and a thickness in the magnetized direction of

The submitted manuscript has been created by the University of Chicago as Operator of Argonne National Laborarory ("Argonne") under Contract No. W-31-109-ENG-38 with the U.S. Deparment of Energy. The U.S. Government retains for itself, and others acting on its behalf, a paid-up, nonexclusive. irrevocable worldwide license in said article to reproduce. prepare derivative works. distribute copies to the public. and perform publicly and displizy publicly. by or on behalf of the Government. 


\section{DISCLAIMER}

This report was prepared as an account of work sponsored by an agency of the United States Government. Neither the United States Government nor any agency thereof, nor any of their employees, make any warranty, express or implied, or assumes any legal liability or responsibility for the accuracy, completeness, or usefulness of any information, apparatus, product, or process disclosed, or represents that its use would not infringe privately owned rights. Reference herein to any specific commercial product, process, or service by trade name, trademark, manufacturer, or otherwise does not necessarily constitute or imply its endorsement, recommendation, or favoring by the United States Government or any agency thereof. The views and opinions of authors expressed herein do not necessarily state or reflect those of the United States Government or any agency thereof. 


\section{DISCLAMMER}

Portions of this document may be illegible in electronic image products. Images are produced from the best available original document. 
$12.7 \mathrm{~mm}$. The residual induction and coercive force of the blocks were approximately $1.1 \mathrm{~T}$ and $10.5 \mathrm{kOe}$, respectively. For the temperature compensation flux shunts, $1.27-\mathrm{mm}$-thick and $25-\mathrm{mm}$-wide strips of $30 \%-\mathrm{Ni}$ $\mathrm{Fe}$ alloy were used. The alloy has a Curie temperature of $60^{\circ} \mathrm{C}$ and saturation induction of $0.22-0.1 \mathrm{~T}$ at $20-45^{\circ} \mathrm{C}$.

First a dipole magnet without temperature compensators was put in a temperature-controlled incubator and its temperature and the magnetic field in the air gap were measured. The magnet was assembled using six NdFeB blocks in each of the top and bottom poles. Figure 2 shows that the temperature coefficient for the relative magnetic field $(\Delta \mathrm{B} / \mathrm{B}) / \Delta \mathrm{T}$ in the air gap was $-1.1 \times 10^{-3} /{ }^{\circ} \mathrm{C}$ in the temperature range of $25-45^{\circ} \mathrm{C}$. The Hall probes used for the magnetic field measurements were calibrated to $\pm 10^{-5}$ of reading $/{ }^{\circ} \mathrm{C}$ with a resolution of $0.2 \mathrm{G}$. The temperature measurement has an absolute accuracy of $0.5^{\circ} \mathrm{C}$ with a resolution of $0.1^{\circ} \mathrm{C}$.

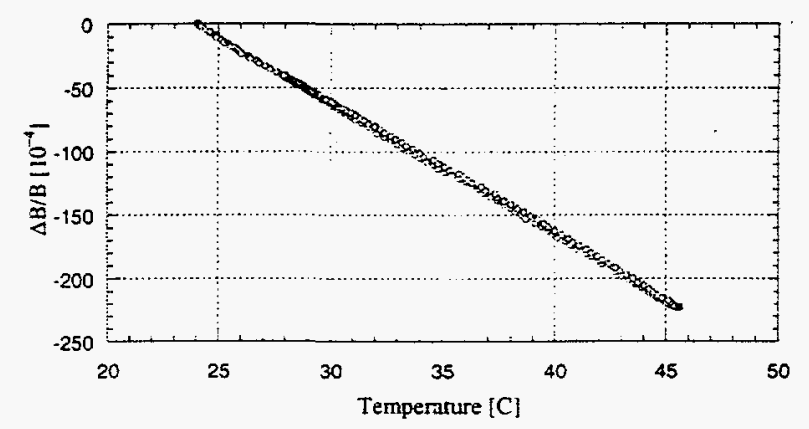

Figure 2: Magnetic field data under a slow thermal cycle for a $\mathrm{NdFeB}$ permanent dipole magnet. Temperature coefficient for the relative magnetic field in the air gap was $(\Delta \mathrm{B} / \mathrm{B}) / \Delta \mathrm{T}=-1.1 \times 10^{-3} /{ }^{\circ} \mathrm{C}$ in the te :perature range of $25-35^{\circ} \mathrm{C}$.

The data shown in Fig. 3 are measurements of a magnet with an optimum number of temperature compensation strips. The volume ratio of the strip/NdFeB for the magnet was $20 \%$. In this magnet the compensation strips were inserted between the gaps of the NdFeB blocks as shown the top view in Fig 1(b). The strips cannot be distributed uniformly, but the magnetic field distribution in the air gap can be adjusted by the geometry of the magnet poles. The measured data show that within the relative field variation of $2 \times 10^{-4}$, the temperature coefficient was less than $2 \times 10^{-5} /{ }^{\circ} \mathrm{C}$ in the temperature range of $31 \pm 6^{\circ} \mathrm{C}$. (For better control of the temperature inside the incubator, the temperature at the compensation field was set higher than the room temperature.) In the whole range of the thermal cycle the coefficient was less than $1 \times 10^{-4} /{ }^{\circ} \mathrm{C}$.
During measurement the temperature was controlled at a rate of approximately $0.8^{\circ} \mathrm{C} / \mathrm{hr}$ to ensure the uniformity of the magnet temperature.

Ideally the magnetic field in the air gap can be calculated from the magnetomotive force of the NdFeB blocks as well as the reluctances of the air gap and the compensation strips. Because of the nonlinear magnetic properties of the strips, however, the temperature range for a fully compensated field is limited. The relative magnetic permeability of the strips in the magnet was calculated to be less than 5 .

Figures 4(a) and (b) show the effects of consecutive thermal cycles on the compensated field and temperature. The temperature of the magnet was controlled rather slowly at a rate of only $0.15^{\circ} \mathrm{C} / \mathrm{h}$. The compensated relative magnetic field increased by approximately $1 \times 10^{-4}(0.5 \mathrm{G})$ for the first to the third cycle. On the other hand, the temperature at the compensated field decreased approximately $1^{\circ} \mathrm{C}$. After an additional seven thermal cycles, the compensated fields and temperatures remained within $0.1 \mathrm{G}$ and $0.5^{\circ} \mathrm{C}$, respectively.

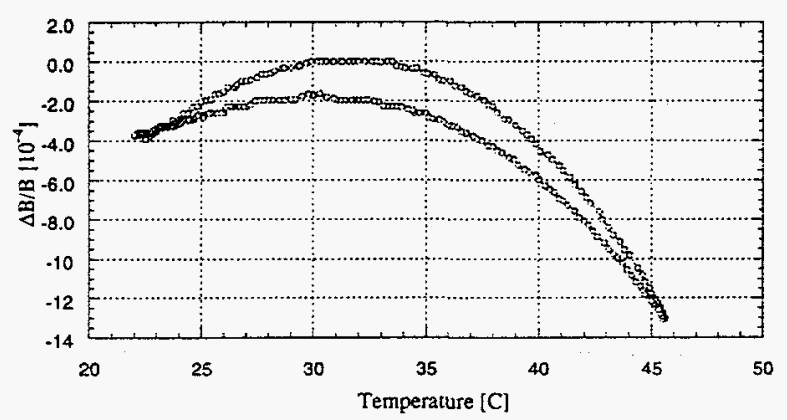

(a)

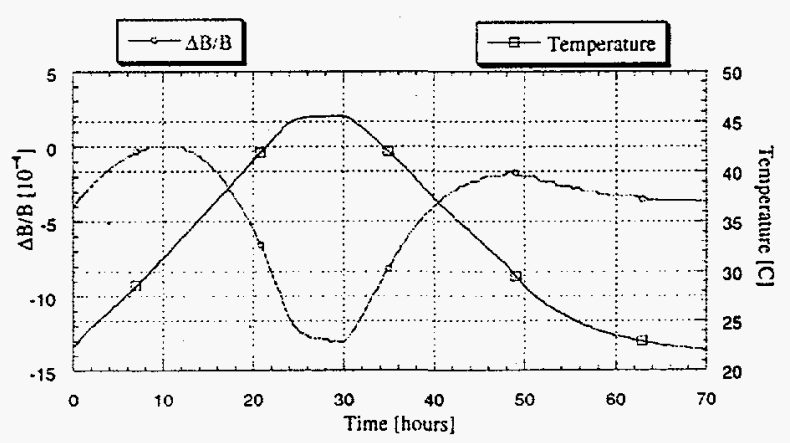

(b)

Figure 3: Temperature compensation of a dipole magnet with a volume ratio of the compensation strip/NdFeB of $20 \%$, the temperature coefficient was $1.7 \times 10^{-5}$ in the temperature range of $31 \pm 6^{\circ} \mathrm{C}$. (a) $\triangle \mathrm{B} / \mathrm{B}$ vs. temperature and (b) $\Delta B / B$ and temperature vs. time. 


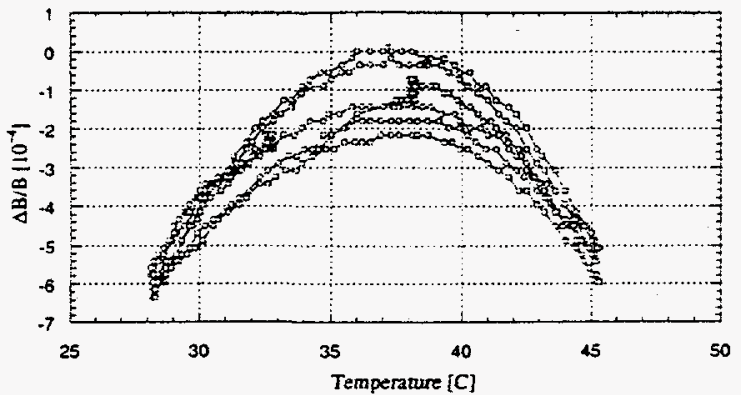

(a)

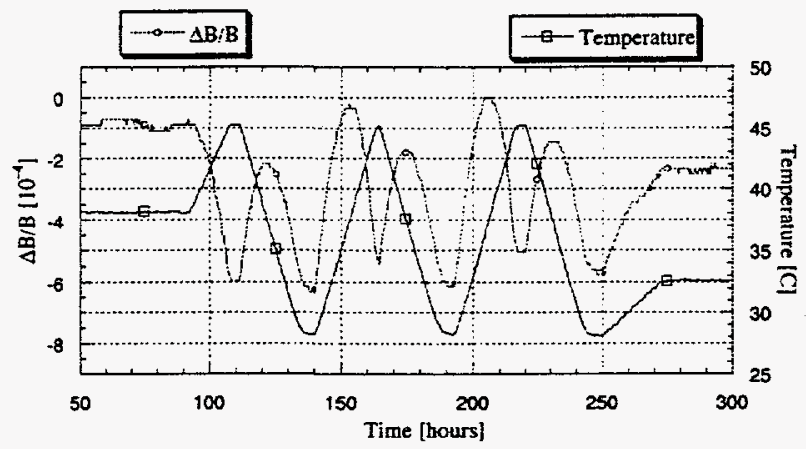

(b)

Figure 4: Three thermal cycles of a compensated dipole magnet at a thermal cycle rate of $0.15^{\circ} \mathrm{C} / \mathrm{h}$ (a) $\triangle \mathrm{B} / \mathrm{B}$ vs. temperature and (b) $\Delta \mathrm{B} / \mathrm{B}$ and temperature vs. time.

\section{SUMMARY}

The temperature coefficients of $\mathrm{NdFeB}$ permanent magnets were reduced from $-1.1 \times 10^{-3} /{ }^{\circ} \mathrm{C}$ to less than $2 \times$ $10^{-5} /{ }^{\circ} \mathrm{C}$ under operating temperatures of $\pm 6^{\circ} \mathrm{C}$ by passively using Ni-Fe alloy as flux shunts for the $\mathrm{NdFeB}$ blocks. After the initial increase of the compensated field by $1 \times 10^{-4}$ in the first three thermal cycles, the field remained within $2 \times 10^{-5}$ after an additional seven thermal cycles. The effects of thermal cycles, aging, and radiation have to be investigated further.

\section{ACKNOWLEDGMENTS}

This work was supported by the U.S. Department of Energy, Office of Basic Energy Sciences, under Contract No. W-31-109-ENG-38.

\section{REFERENCES}

[1] Rollin J. Parker, Advances in Permanent Magnetism, John Wiley \& Sons, New York, 1990.

[2] K. Bertsche, J.-F. Ostiguy, and W. B. Foster, "Temperature Considerations in the Design of a Permanent Magnet Storage Ring," Proc. of the 1995 Particle Accelerator Conference, IEEE 95CH35843, pp. 1381-1383 (1996). 